\title{
Environmental Uncertainty, Comprehensive Performance Measurement Systems, Performance-Based Compensation, and Organizational Performance
}

\author{
Axel K-D. Schulz ${ }^{\mathrm{a}^{*}}$, Anne Wu $\mathrm{Wu}^{\mathrm{b}}$ and Chee W. Chow ${ }^{\mathrm{c}}$ \\ ${ }^{a}$ Monash University \\ ${ }^{b}$ National Chengchi University \\ ${ }^{c}$ San Diego State University
}

\begin{abstract}
This study explores firms' use of comprehensive performance measures and performancebased compensation in response to the increasingly uncertain competitive environment. Data from a sample of 84 Taiwanese high-tech manufacturing firms revealed an increased use of such systems among firms facing higher perceived environmental uncertainty. We also found performance-based pay to fully mediate the relationship between comprehensive performance measures and employee effort. Finally, employee effort is significantly and positively associated with organizational performance and fully explains the effect of performance-based compensation in increasing organizational performance.
\end{abstract}

JEL classifications: M40, M52

Keywords: Comprehensive performance measurement, performance-based compensation, employee effort, organizational performance, environmental uncertainty

\section{Introduction and Overview}

This study examines the extent to which firms' use of comprehensive performance measures and performance-based compensation is responsive to the uncertainty in their competitive environment. It also explores the avenues whereby these management practices affect employee effort and organizational performance. This topic is important because the global economy is becoming increasingly uncertain, with rapid technological advances, constantly changing customer demands, increased

\footnotetext{
* Corresponding author: Axel K-D. Schulz, Department of Accounting and Finance, Monash University, 900 Dandenong Rd, Caulfield East, Vic, 3145, Australia.

The authors would like to acknowledge the helpful comments of Hsihui Chang and Rob Chenhall.
} 
deregulation and the dismantling of trade barriers Mia and Clarke (1999), Leifer et al (2001), Puranam et al (2006). A firm's management accounting related practices can significantly affect its chances of survival and success in this turbulent environment as per Chenhall and Morris (1986), Kaplan and Norton (2001), Chenhall (2003), Van der Stede et al (2006), Langfield-Smith (2007), and as such improved understanding of how such practices affect firm performance is important to management effectiveness.

Relating to performance measurement, both academics and practitioners have argued that while traditional financial measures are useful for summarizing organizational performance, they are inadequate for meeting the challenges of today's marketplace, as per Eccles (1991), Fisher (1992), Kaplan and Norton (1996), Ittner and Larcker (1998), Neely (1999). Many authors have pushed for improving the financial measures, e.g. Stern et al (2004), while others have promoted increased use of non-financial (including subjective) performance measures, e.g. Kaplan and Norton (1996, 2001). While differences exist across the systems proposed by different authors, they share a common emphasis on tying performance measures to the firm's strategic objectives, as per Hall (2007). The claim is that diverse, balanced and integrated ("comprehensive" for short) performance measurement systems can improve firms' ability to translate strategy into performance targets, communicate expectations to employees, monitor performance, provide feedback for improvement, and motivate employees towards target attainment, as per Van der Stede et al (2006).

Despite the intuitive appeal of comprehensive performance measurement (CPM) systems, extant research into their nature and effects is partial and incomplete. The majority of studies to date have either investigated the link between perceived environmental uncertainty (PEU) and the perceived usefulness of performance measurement systems, such as Gordon and Narayanan (1984), Kren and Kerr (1993), see Tymon et al (1998) and Chenhall (2003) for reviews, or the link between use of these systems and individual -- but not organizational performance, for example Gul and Chia (1994), Chong (1996), see Tymon et al (1998). While Govindarajan (1984) did examine the link to business unit performance, its focus was superiors' evaluation style in using performance information, rather than the extent to which the performance measures are diverse, balanced and integrated. Furthermore, to the extent that performance measurement design is a response to the environment rather than an exogenous firm attribute, eg Tymon et al (1998), Luft and Shields (2003), Chenhall (2007), simultaneously examining all the linkages that flow from PEU to CPM, and from the latter to employee effort and organizational performance, is important for accurately identifying the factors that drive organizational performance and the pathways of their effects. ${ }^{1}$

In conducting such an investigation, a further consideration is that firms' design of performance measurement systems often is linked to another key management control: the compensation system. Theoretical models have long stipulated that linking individual performance to monetary rewards increases individual effort and performance, viz Vroom (1964), Lawler (1973), see Bonner et al (2002) for a review.

\footnotetext{
${ }^{1}$ To the extent that the various elements are inter-related, tests that only consider subsets of the relationships in isolation from the others could yield biased results and inferences. This is because the effects of one factor on another may be affected by the levels of the other factors in the causal chain.
} 
A critical decision in designing performance-based compensation (PBC) systems is the proportion of compensation that is tied to performance outcomes. Employees tend to concentrate on those activities for which their performance is measured, often at the expense of other relevant but non-measured activities, see Hopwood (1974), Hayes et al (1988). A broader range of performance measures can reduce employees' opportunities to "game the system", see Robertson (2005), thus curtailing such dysfunctional effects. Analytical studies by Datar et al. (2001), Feltham and Xie (1994), Hemmer (1996), Holmstrom (1979), and Lambert (2001), for example, have demonstrated that in the absence of measurement costs, introducing incentives based on non-financial measures can improve contracting by incorporating information on managerial actions that are not fully captured by financial measures. Baker et al. (1994) and Baiman and Rajan (1995) have shown that subjective measures can help to mitigate distortions in managerial effort by "backing out" dysfunctional behaviors induced by incomplete objective performance measures, as well as reduce noise in the overall performance evaluation. Thus, it stands to reason that firms which use more comprehensive performance measures also would have greater assurance of positive outcomes from using PBC, see Banker et al. (2000), Ittner et al. (1997). To our knowledge, extant research on CPMs has yet to explore the extent to which their performance effects arise from the nature of the performance measures (which has to do with the adequacy of information for coping with uncertainty), or are due to employees increasing their effort in response to the increased use of PBC enabled by more comprehensive performance measures (thus a motivational effect). Correct identification of this causal path can help the effective deployment of CPMs, and our study includes such an investigation.

Consistent with our postulate that the various elements are inter-related rather than disjoint pieces, we used partial least squares to simultaneously assess the linkages that flow from PEU through CPM/PCB to employee effort and organizational performance. Data were collected from a sample of 84 Taiwanese manufacturing firms in the telecommunications, electronics, and information technology sector. The results reveal a positive relation between PEU and CPM, and between CPM and PCB. We also find that the use of PBC fully mediates the relationship between CPM and employee effort (EEF). In turn, EEF is significantly and positively associated with organizational performance, and fully mediates the link between PBC and organizational performance.

The remainder of this paper is structured as follows. The next section develops our hypotheses. Then in section 3 , we provide details of the methods used to collect data and to test the hypotheses. Section 4 presents the results. Section 5 concludes the paper with a summary and discussion.

\section{Hypothesis Development}

Environmental uncertainty has been of interest to designers of organizations for many decades e.g., Burns and Stalker (1961), Lawrence and Lorsch (1967), Perrow (1970), and Galbraith (1973). Much of this work has focused on how organizations change their structure in response to changes in the level of environment uncertainty. In the accounting literature, Khandwalla (1972) and Gordon and Narayanan (1984) 
were among the earliest studies to investigate management control system responses to environmental uncertainty.

Interest in environmental uncertainty has remained strong in the accounting literature as markets have become increasingly dynamic and innovations have appeared in the design of accounting control systems. The thrust of such innovations has been towards more comprehensive performance measurement systems that involve increased use of non-financial performance measures, recognition of lead-lag relationships, integration of measures across organizational sub-units and hierarchical levels, and tying performance measures to the firm's competitive strategy e.g., the balanced scorecard, Kaplan and Norton (1996) and the Tableau de Bord, Epstein and Manzoni (1998). Empirical research has supported the potential usefulness of broad-scope management accounting information, e.g. Gordon and Narayanan (1984), Chenhall and Morris (1986), Gul and Chia (1994), Chong (1996), Chong and Chong (1997), see Chenhall (2003, 2007) for a review. Consistent with Galbraith's view of uncertainty and uncertainty reduction, the explanation has centered primarily on the gap between information available to individuals versus what they need to cope with uncertainty. While this body of research has only considered some aspects of performance measurement comprehensiveness, it is reasonable to expect that CPM, which goes far beyond just increasing the diversity or scope of performance measures, would further enhance the information that firms and their employees can use in responding to increased uncertainty, see Ittner and Larcker (2001), Kaplan and Norton (1996). This inference is consistent with early work by Khandwalla (1972), who documented an increase of performance measurement sophistication (although in his case solely based on financial measures) in response to increased PEU. Others who have studied the effects of measurement diversity, e.g., Ittner et al (2003) and the use of non-financial performance measures, e.g., Ittner and Larcker (1995) also have attributed the perceived importance or consequences of such changes in performance measurement to the additional information that they provide to individuals in the organization. Thus we hypothesize:

Hypothesis 1: Use of comprehensive performance measurement systems is positively associated with the level of perceived environmental uncertainty. ${ }^{2}$

And, to the extent that CPM serves a decision facilitating role as hypothesized above, it should help to improve organizational performance. A number of prior studies have examined the performance effects of performance measure diversity, with mixed results. Some studies, such as Scott and Tiessen (1999) and Hoque and James (2000), have found positive effects, with the former documenting an increase in team performance from the use of more diverse measures, and the latter reporting performance effects from measurement diversity at the organizational level. In contrast, Ittner et al. (2003) failed to find a performance increase from the use of more diverse measures. Besides being limited to only a small part of the causal links ending in organizational performance, these studies have only examined one aspect - diversity — of performance measurement

\footnotetext{
${ }^{2}$ Following prior research, we focus on perceptions of uncertainty rather than any objective measures of this variable. This is because it is how people perceive their external environment that affects decision-making in organizations, Dill (1958).
} 
systems. Thus, the need remains to explore whether comprehensive performance measures - ones that are diverse, balanced and integrated - have positive performance effects. As will become clear from our discussion below, our second hypothesis also provides a baseline for differentiating among direct and indirect effects of CPM on organizational performance:

Hypothesis 2: Use of comprehensive performance measures is positively associated with organizational performance.

But beyond serving a decision facilitating role, comprehensive performance measures also can have motivational effects. Greater performance measure comprehensiveness also provides employees with a more integrated perspective on how effort exerted in their particular areas of operations translate into overall firm performance. Both expectancy theory, e.g. Lawler (1973), and expected utility theory, e.g. Baiman (1990), suggest that when people have a strengthened or clearer understanding of the link between their effort and performance outcomes, they would be more motivated to exert effort. Thus we hypothesize:

Hypothesis 3: Use of comprehensive performance measures is positively associated with employee effort.

Furthermore, as a firm increases the comprehensiveness of its performance measures, it also has increased leeway to employ performance-based compensation (PBC) systems, and it is well established that linking performance outcomes to monetary rewards can motivate increased employee effort, see Bonner and Sprinkle (2002) for a review. Of relevance to our study, it has been noted that if the performance measurement system is too narrow in scope, using it as the basis for compensation can be vulnerable to individuals in the organization "gaming the system," particularly where superiors have difficulties observing the actions of their subordinates, see Robertson (2005). Since a more comprehensive performance measurement system taps into more aspects of organizational performance, it should reduce the information asymmetry between superior and subordinate. Thus, organizations with more comprehensive performance measures also should have greater assurance of positive effects from using PBC.

Much of the empirical work to date has examined whether organizations link compensation to performance dimensions other than the financial component, e.g. Banker et al. (2000), or the performance implications of including these other dimensions in the performance evaluation system, e.g. Ittner et al. (2003). The analytical literature, e.g. Feltham and Xie (1994), Holmstrom (1979), has concluded that measures other than financial ones should be included in management compensation contracts (subject to their cost and risk imposed on the managers) as long as they provide incremental information about managers' actions. However, this literature has omitted consideration of whether the increased use of CPM is an antecedent to PBC use in organizations. ${ }^{3}$ Our next hypothesis provides focus to such an investigation:

\footnotetext{
${ }^{3}$ As explained further below, clarifying this link is important to understanding how a firm can best benefit from CPM usage.
} 
Hypothesis 4: Use of performance-based compensation increases with the use of comprehensive performance measures.

Numerous studies have investigated whether performance-based compensation increases employee effort, see Bonner and Sprinkle (2002) for a review, and a recent review of the laboratory-based studies, see Bonner et al. (2000), has shown PBC to be effective. However, much of this research has been confined to single-goal tasks under low or no uncertainty. In contrast, uncertainty is a fact of life in organizations, where an increased use of PBC also imposes greater risk on individual employees, see Baiman (1990). The likely consequence is that individuals will either demand higher compensation, or withhold effort in the absence of such an adjustment, see Umanath et al. (1993). But when the firm uses a more comprehensive performance measurement system, the risks to individual employees under PBC are reduced, and the motivating effects of PBC on effort should become more dominant. This proposition is consistent with Kren and Kerr (1993), who argued that organizations need to invest in better information systems when using PBC under uncertainty. In a study of time-series data in 18 hotels, Banker et al. (2000) found that when non-financial measures are included in the compensation contract, managers more closely aligned their efforts to those measures, resulting in increased performance. Scott and Tiessen (1999) and Hoque and James (2000) have reported similar results. Findings like these provide the basis for the following hypothesis.

Hypothesis 5: Use of performance-based compensation is positively associated with employee effort.

Taken together, H3, H4 and H5 allow for both direct and indirect effects on EEF from the use of CPMs. As we had explained earlier, the direct effect from CPM to effort is based on the argument that CPM reduces employees' uncertainty in assessing the relation between their inputs and measured outputs, and that this increased expectancy increases individual effort to improve their measured performance. In contrast, the indirect effect is predicated on the use of CPMs facilitating the use of PBCs, with the latter motivating increased effort. Resolving whether CPM only has a direct effect on effort, or whether there is an indirect effect via PBC, and to what extent this indirect effect mediates any direct effect has important implications for how a firm can best leverage the effects of its performance measurement system. For example, if PBC fully mediates the effect of CPM on effort, then the design of CPM cannot be used to increase employee effort except through PBC. On the other hand, if PBC only partially mediates CPM's effects - thus CPM has both a direct and indirect effect (via PBC) on effort then the design of both CPM and PBC can influence employees' effort choices. ${ }^{4}$

Finally, we recognize that there are two separate routes whereby PBC can affect organizational performance. The prior incentive literature, see Sprinkle (2000) for a review, points to an indirect effect via effort and thus the following proposition:

\footnotetext{
${ }^{4}$ More discussion of mediating effects is available in Baron and Kenny (1986), Hartmann and Moers (1999), and Gerdin and Greve (2004).
} 
Hypothesis 6: Employee effort is positively associated with organizational performance.

But the existence of an indirect effect does not preclude there also being a direct effect from PBC to performance. Based on the goal setting literature, see Hirst (1987), to the extent $\mathrm{PBC}$ reinforces specific performance targets, individual employees will be motivated to seek more effective means of performing their tasks, without necessarily increasing their effort level. Thus we hypothesize:

Hypothesis 7: Performance-based compensation is positively associated with organizational performance.

Taken together, H5, H6 and H7 focus on whether PBC affects organizational performance directly, or indirectly via its impact on EEF. In conjunction with $\mathrm{H} 3$ and $\mathrm{H} 4$, they provide a structure for understanding how a firm's design of its performance measurement system ultimately translates into impacts on organizational performance.

\section{Research Method}

\subsection{Sample and procedure}

We focused on manufacturing companies in the telecommunications, electronics, and information technology sector for two major reasons, the first being to limit extraneous influences due to different industry types. Second, uncertainty is high for firms in this sector due to rapid technological advances and highly competitive markets, see Carey and Nahavandi (1996), Schilling and Hill (1998), Balkin et al. (2000).

We used a database of published financial statements (the "Taiwan Economic Journal Taiwan Data Bank") to identify all Taiwanese companies in the target sector with shares that were traded on the Taiwan Stock Exchange or over-the-counter. Of 711 companies identified through this search, we sought a sample of 100 companies in consideration of budgetary constraints and the target respondents' high hierarchical levels. We randomly selected 100 companies, and solicited their participation by approaching a high-level manager (vice president or above) with the aid of accounting and consulting firms. As we encountered (initial) refusals to participate, replacements were randomly selected. In total, we approached 115 companies, of which 106 ultimately participated. Each company provided a contact person for receiving and distributing the surveys.

To reduce the threat of common methods bias, where one informant self-reports on all of the constructs in the study, see Podsakoff and Organ (1986) for a discussion, we distributed two different surveys in each firm. ${ }^{5}$ The "Top Management Survey" sought information on the company's external environment, employee effort and a subjective assessment of performance. It was targeted at top-level managers because

\footnotetext{
${ }^{5}$ We also conducted the Harman single-factor test for common methods variance. We found no evidence of common methods bias as more than one single factor emerged and no one major factor accounted for the majority of covariance in the independent and criterion variables.
} 
they usually are the most knowledgeable source for this kind of information, particularly with regard to PEU and organizational performance, see Snow and Hrebiniak (1980), Tymon et al. (1998). The "Human Resource Manager Survey" was targeted at a highlevel human resource or personnel manager, and sought information on the performance measurement system and the compensation system.

Administration of the survey included the following steps. First, because the survey was administered in Chinese, Brislin's (1986) recommendation of translation and back-translation was followed to ensure conceptual equivalence between the original instruments (in English) and the Chinese versions. Both surveys were first translated into Chinese by a bilingual individual who was not told the objective of the study, then another bilingual person back-translated these into English without having access to the original instruments. Only a few minor changes were made to the Chinese surveys based on comparing the back-translated and original English versions.

Second, each contact person was given explicit instructions on the appropriate type of manager to complete each version of the survey. In addition to level and functional area (top-level or HR manager), each manager had to have a minimum of three years' tenure at the firm. To encourage truthful responses to sensitive questions, complete confidentiality and anonymity were guaranteed, and a postage-paid, self-addressed envelope was provided for direct return of completed surveys. Since responses were obtained from two different managers in each company, both surveys provided to a company had a common identification code so that they could be combined for analysis, and this was explained in a cover letter to the respondents. Participants who had any questions regarding the survey could contact the Taiwan-based co-author directly to get clarification.

Of the 106 companies that participated, 22 only returned one completed survey. Since our analysis required information from both surveys, these companies were excluded, leaving 84 firms in our final sample. The retained respondents to the Top Management Survey were distributed among positions as follows: chief financial officer $(25.5 \%)$, vice president $(19.8 \%)$, chief executive officer $(6.6 \%)$, chairman of the board $(2.8 \%)$, vice chairman of the board $(2.8 \%)$, and others such as general managers, business directors, and special assistants to the chief executive officer $(42.5 \%)$. On average, the respondents had been in their current jobs for over nine years. The majority of respondents to the Human Resource Manager Survey were managers of human resources $(53.8 \%)$. The remainder were directors of human resources $(12.3 \%)$, vice presidents of HRM $(0.9 \%)$, and others such as general managers and special assistants to the manager of human resources $(33 \%)$. Their average tenure in the current position was over five years. Thus, both groups of respondents should be sufficiently knowledgeable about their organizations to provide informed responses.

\subsection{Measurement of variables}

Multi-item scales were used for each variable. All scales were based as closely as possible on prior empirical research. Table 1.1 presents the items comprising each scale in our study. 
Table 1.1: Composite Reliability and AVE Scores for Perceived Environmental Uncertainty, Comprehensive Performance Measurement, Performance Based Compensation, Employee Effort, and Organizational Performance

Panel A Perceived Environmental Uncertainty (Composite Reliability=0.841, AVE=0.640)

\begin{tabular}{|l|l|}
\hline $1-1$ & How stable is the economic external environment facing your company \\
\hline $1-2$ & How stable is the technological external environment facing your company \\
\hline $1-3$ & How stable is the political/regulatory environment facing your company \\
\hline
\end{tabular}

Panel B Comprehensive Performance Measures (Composite Reliability=0.915, AVE=0.685)

\begin{tabular}{|l|l|}
\hline $2-1$ & Performance evaluation uses a mix of financial and non-financial (including subjective) measures \\
\hline $2-2$ & Performance measures are systematically tied across levels of the company's hierarchy \\
\hline $2-3$ & $\begin{array}{l}\text { A mix of leading (e.g. customer satisfaction) and lagging indicators (e.g. sales) is used to evaluate } \\
\text { performance }\end{array}$ \\
\hline $2-4$ & $\begin{array}{l}\text { Performance evaluation uses a mix of measures that are explicitly identified with different aspects } \\
\text { of performance (e.g. customer satisfaction, internal operations, learning and growth) }\end{array}$ \\
\hline $2-5$ & Performance evaluation is explicitly tied to the company's competitive strategy \\
\hline
\end{tabular}

Panel C Performance-Based Compensation (Composite Reliability $=0.835, \mathrm{AVE}=0.559$ )

\begin{tabular}{|l|l|}
\hline $3-1$ & $\begin{array}{l}\text { People's compensation contracts clearly specify how their compensation is based on their perfor- } \\
\text { mance }\end{array}$ \\
\hline $3-2$ & People's compensation increase as their performance increases \\
\hline $3-3$ & $\begin{array}{l}\text { People whose performance ranks in the top } 25 \% \text { receive higher compensation than people who } \\
\text { rank in the bottom } 25 \%\end{array}$ \\
\hline $3-4$ & Compensation is directly tied to individual performance \\
\hline
\end{tabular}

Panel D Employee Effort (Composite Reliability=0.921, AVE=0.795)

\begin{tabular}{|l|l|}
\hline $4-1$ & People are always ready to "go the extra mile" for the sake of the company \\
\hline $4-2$ & People take pride in working hard for the company \\
\hline $4-3$ & People always put forth a high level of effort at work \\
\hline
\end{tabular}

Panel E Organizational Performance (Composite Reliability=0.967, AVE=0.743)

\begin{tabular}{|l|l|}
\hline & Over the past three years how did your company's performance compare to that of your industry: \\
\hline $5-1$ & Long run level of firm profitability \\
\hline $5-2$ & Growth rate of sales and revenues \\
\hline $5-3$ & Level of return on assets \\
\hline $5-4$ & Trend of return on assets \\
\hline $5-5$ & Market share \\
\hline $5-6$ & Operational and cost efficiency \\
\hline $5-7$ & Productivity \\
\hline $5-8$ & Level of return on sales \\
\hline $5-9$ & Trend of return on sales \\
\hline $5-10$ & Overall performance \\
\hline
\end{tabular}

As explained further below, we used partial least squares (PLS) to test the hypotheses. PLS provides a composite reliability score (equivalent to Cronbach alpha) for assessing 
the convergent validity of each construct, and the average variance extracted (AVE) to assess its divergent validity, see Fornell and Larcker (1981). ${ }^{6}$ The generally acceptable level of AVE is 0.50 or higher, see Hair et al. (1998). In addition, the square root of the average AVE for each construct should exceed the correlations shared between the construct and other constructs in the model, see Fornell and Larcker (1981). Table 1.1 contains all the indicators included in the PLS model as well as the composite reliability score for each construct. It shows that all of our constructs exceed the suggested 0.70 cut-off for composite reliability, see Nunnally and Bernstein (1994). We report the AVE for each construct and the comparison of the square root AVE in Tables 1.2 and 3 respectively. All of our constructs meet both thresholds. Further, we report the loadings as well as the t-statistics for each item making up a particular construct in Table 1.2. All items load above 0.65 and all loadings are significant.

Table 1.2: Indicator Loadings and T-Statistics

\begin{tabular}{|c|c|c|}
\hline Item & Loading & T-Statistic \\
\hline \multicolumn{3}{|c|}{ Perceived Environmental Uncertainty (PEU) Composite Reliability $=0.841$, AVE $=0.640$} \\
\hline $1-1$ & 0.879 & 7.902 \\
\hline $1-2$ & 0.820 & 6.883 \\
\hline $1-3$ & 0.689 & 3.778 \\
\hline \multicolumn{3}{|c|}{$\begin{array}{l}\text { Comprehensive Performance Measures }(\mathrm{CPM}) \text { Composite Reliability }=0.915, \mathrm{AVE}= \\
0.685\end{array}$} \\
\hline $2-1$ & 0.730 & 10.934 \\
\hline $2-2$ & 0.844 & 29.042 \\
\hline $2-3$ & 0.814 & 15.789 \\
\hline $2-4$ & 0.882 & 33.356 \\
\hline $2-5$ & 0.860 & 24.212 \\
\hline \multicolumn{3}{|c|}{ Performance-Based Compensation (PBC) Composite Reliability = 0.835, AVE = 0.559 } \\
\hline $3-1$ & 0.781 & 14.033 \\
\hline $3-2$ & 0.791 & 15.824 \\
\hline $3-3$ & 0.647 & 6.284 \\
\hline $3-4$ & 0.763 & 11.582 \\
\hline \multicolumn{3}{|c|}{ Employee Effort (EEF) Composite Reliability = 0.921, AVE = 0.795 } \\
\hline $4-1$ & 0.878 & 23.983 \\
\hline $4-2$ & 0.890 & 25.703 \\
\hline $4-3$ & 0.905 & 42.210 \\
\hline \multicolumn{3}{|c|}{ Organizational Performance $(\mathrm{PF})$ Composite Reliability $=0.967, \mathrm{AVE}=0.743$} \\
\hline $5-1$ & 0.882 & 38.945 \\
\hline $5-2$ & 0.805 & 17.633 \\
\hline $5-3$ & 0.882 & 34.704 \\
\hline
\end{tabular}

${ }^{6}$ Unlike the Cronbach Alpha index, the composite reliability index reflects the differential weights used by PLS for the indicators underlying each construct. 


\begin{tabular}{|l|l|l|}
\hline $5-4$ & 0.892 & 41.492 \\
\hline $5-5$ & 0.829 & 25.753 \\
\hline $5-6$ & 0.889 & 38.593 \\
\hline $5-7$ & 0.847 & 19.986 \\
\hline $5-8$ & 0.888 & 28.166 \\
\hline $5-9$ & 0.810 & 19.135 \\
\hline $5-10$ & 0.892 & 41.613 \\
\hline
\end{tabular}

\section{Perceived Environmental Uncertainty}

Perceived environmental uncertainty was measured with questions adapted from Khandwalla's (1977) instrument. Respondents were asked how stable/dynamic was the firm's external environment on three dimensions: economic, technological and political. The 7-point response scale was anchored by 1 = "very stable" and 7 = "very dynamic." The composite reliability score is 0.841 and the AVE is 0.640 .

\section{Use of Comprehensive Performance Measures}

To measure the extent to which a firm used a comprehensive performance measurement system, we developed five statements based on an extensive review of the literature, see Abernethy and Lillis (1995), Epstein and Manzoni (1997, Fisher (1992), Hoffecker and Goldenberg (1994), Maisel (1992), Kaplan and Norton (1992, 1996, 2001), Provost and Leddick (1993), and Scott and Tiessen (1999). Respondents were asked to indicate on a 7-point Likert scale the extent to which they agreed or disagreed ( 1 = "strongly disagree" and 7= "strongly agree") that each statement applied to their company: "Performance evaluation uses a mix of financial and non-financial (including subjective) measures," "Performance measures are systematically tied across levels of the company's hierarchy," "A mix of leading (e.g., customer satisfaction) and lagging indicators (e.g., sales) is used to evaluate performance," "Performance evaluation uses a mix of measures that are explicitly identified with different aspects of performance (e.g., customer satisfaction, internal operations, learning and growth)," and "Performance evaluation is explicitly tied to the company's competitive strategy." The composite reliability score is 0.915 and the AVE is 0.685 .

\section{Use of Performance-based Compensation}

Questions used to measure the use of performance-based compensation were adapted from Chow et al. (1999) and Shields and Young (1993). Respondents were asked to indicate on a 7-point Likert scale the extent to which they agreed or disagreed ( 1 = "strongly disagree" and $7=$ "strongly agree") that each of these statement applied to their company: "People's compensation contracts clearly specify how their compensation is based on their performance," "People's compensation increase as their performance increases," "People whose performance ranks in the top $25 \%$ receive higher compensation than people who rank in the bottom 25\%," and "Compensation is 
directly tied to individual performance." The composite reliability score is 0.835 and the AVE is 0.559 .

\section{Employee Effort}

Three questions were used to measure employee effort. Respondents were asked to indicate their degree of agreement or disagreement ( $1=$ "strongly disagree" and $7=$ "strongly agree") with these statements: "People are always ready to "go the extra mile" for the sake of the company," "People take pride in working hard for the company," and "People always put forth a high level of effort at work." The composite reliability score is 0.921 and the AVE is 0.795 .

\section{Organizational Performance}

Given the lack of consensus regarding a valid cross-industry measure of corporate performance Tan et al. (1999), we followed the approach used by Tan et al. (1998) and Tan et al. (1999) to solicit senior managers' perceptions of their firms' overall performance. Respondents were asked to indicate how well their firm had performed over the past three years as compared to their industry $(1=$ "One of the worst," $7=$ "One of the best") on the following dimensions: "Long run level of firm profitability," "Growth rate of sales and revenues," "Level of return on assets," "Trend of return on assets," "Market share," "Operational and cost efficiency," "Productivity," "Level of return on sales," "Trend of return on sales," and "Overall Performance." The composite reliability score is 0.967 and the AVE is 0.743 .

\subsection{Missing data}

There were only 15 missing data points across the entire set of survey responses, equal to $0.6 \%$ of the total data points possible from the returned surveys. Little's MCAR test indicated that the missing data were completely random, thus allowing us to use any imputation method, Hair et al. (1998). We elected to use the expected-maximization (EM) method, see Dempster et al. (1977), in SPSS 14 to replace missing data. This method involves a two-stage process - expectation (E) and maximization (M). The E stage involves replacing missing values with the best possible estimates, while the $M$ stage involves making parameter estimates based on the imputed values. The two stages are repeated until the changes in the values become negligible, see Little and Rubin (1987), Hair et al. (1998).

\section{Analysis and results}

\subsection{Descriptive statistics}

Given the high internal consistency of each measured variable, we created a latent variable for each construct by obtaining the arithmetic average of its component 
scores. Table 2 presents the descriptive statistics, and Table 3 provides the bivariate correlations among the main latent variables of interest. The latter shows that Perceived Environmental Uncertainty (PEU) is significantly correlated only with the use of Comprehensive Performance Measures (CPM). CPM in turn is significantly correlated with both Performance-based Compensation (PBC) and Employee Effort (EEF). PBC is significantly correlated with EEF as well as Organizational Performance (PF), and EEF is significantly correlated with PF.

Table 2: Descriptive Statistics

\begin{tabular}{|l|c|c|c|c|c|c|}
\hline \multirow{2}{*}{ Variable } & \multirow{2}{*}{ Mean } & \multirow{2}{*}{ SD } & \multicolumn{2}{|c|}{ Actual Range } & \multicolumn{2}{c|}{ Theoretical Range } \\
\cline { 4 - 7 } & & & Min & Max & Min & Max \\
\hline PEU & 4.67 & 1.070 & 2.33 & 7.00 & 1.00 & 7.00 \\
\hline CPM & 4.56 & 1.179 & 1.60 & 7.00 & 1.00 & 7.00 \\
\hline PBC & 4.51 & 1.027 & 2.49 & 7.00 & 1.00 & 7.00 \\
\hline EEF & 4.00 & 0.879 & 3.00 & 7.00 & 1.00 & 7.00 \\
\hline PF & 4.60 & 1.019 & 2.30 & 6.90 & 1.00 & 7.00 \\
\hline N=84 & \multicolumn{7}{|l}{} \\
\hline
\end{tabular}

PEU $=$ Perceived Environmental Uncertainty

$\mathrm{CPM}=$ Comprehensive Performance Measure

$\mathrm{PBC}=$ Performance Based Compensation

$\mathrm{EEF}=$ Employee Effort

$\mathrm{PF}=$ Organizational Performance

Table 3: Correlation of Variables from PLS Model and (Square Root of AVE)

\begin{tabular}{|l|l|l|l|l|l|}
\hline & PEU & CPM & PBC & EEF & PF \\
\hline PEU & $(0.800)$ & & & & \\
\hline CPM & $0.229 *$ & $(0.828)$ & & & \\
\hline PBC & 0.097 & $0.631 * *$ & $(0.748)$ & & \\
\hline EEF & 0.194 & $0.237 *$ & $0.330^{* *}$ & $(0.892)$ & \\
\hline PF & 0.133 & 0.181 & $0.310^{* *}$ & $0.646^{* *}$ & $(0.862)$ \\
\hline
\end{tabular}

PEU $=$ Perceived Environmental Uncertainty

$\mathrm{CPM}=$ Comprehensive Performance Measure

$\mathrm{PBC}=$ Performance Based Compensation

$\mathrm{EEF}=$ Employee Effort

$\mathrm{PF}=$ Organizational Performance

$* p<0.05$ (2-tailed)

$* * p<0.01$ (2-tailed)

\subsection{Testing the hypothesized relationships}

As was noted earlier, we used partial least squares (PLS) to simultaneously test all of the hypothesized linkages. ${ }^{7}$ PLS is a causal modeling technique that overcomes many

${ }^{7}$ We used PLS Graph 3.0 to analyze our data. 
theoretical and estimation problems present in some of the more well known structural modeling programs, such as LISREL and AMOS, see Hulland (1999), and has become increasingly popular in management accounting studies, see Chenhall (2004, 2005) for examples of PLS applications in management accounting research). In particular, this method does not make assumptions about (a) data distributions to estimate model parameters, (b) observation independence, or (c) variables' metrics, see Barclay et al. (1995). As compared to more traditional techniques like ordinary least squares (OLS) regression, PLS also has the advantage of being less vulnerable to measurement errors in variables and the effects of outliers, see Wilcox (1998). These attributes make PLS particularly suitable for testing multivariate main and indirect effects models, especially for small sample sizes as in the present study, see Wold (1985), Sosik and Dworakivsky (1998). PLS generates estimates of standardized $\beta$ s (i.e., path coefficients) for the model paths, which can be used to measure the relationships between latent variables as in OLS regressions, see Chenhall (2004), and see Sambamurthy and Chin (1994) for more information on PLS. In PLS, bootstrapping provides a basis for evaluating parameter estimates, and we used this technique with 1,000 sample replacement to assess the significance of each path coefficient, see Chin (1998b), Chin and Gopal (1995).

Figure 1 shows the overall model used to test our hypotheses. Table 4 presents the standardized path coefficients and t-statistics. It is inappropriate in PLS to use overall goodness-of-fit measures, which are traditionally reported in LISREL or AMOS, as PLS does not make distributional assumptions, see Chin (1998a). Instead, fit is determined in terms of convergence and discriminate validity between the constructs used as well as the $\mathrm{R}^{2}$ (reported in Table 4) associated with each endogenous variable.

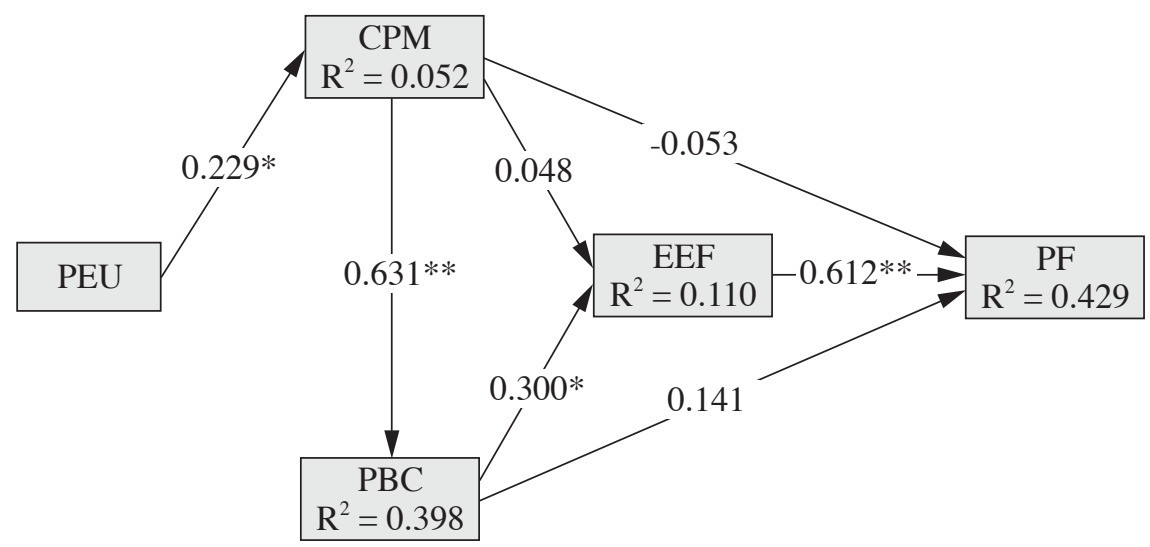

$\begin{aligned} * \mathrm{p} & <0.05(2 \text {-tailed }) \\ * * \mathrm{p} & <0.01(2 \text {-tailed })\end{aligned}$

PEU $=$ Perceived Environmental Uncertainty

$\mathrm{CPM}=$ Comprehensive Performance Measure

$\mathrm{PBC}=$ Performance Based Compensation

$\mathrm{EEF}=$ Employee Effort

$\mathrm{PF}=$ Organizational Performance 
Table 4: PLS Results - standardized path coefficients and ( $t$-statistics), $R^{2}$

\begin{tabular}{|l|l|l|l|l|}
\hline $\begin{array}{l}\text { Independent } \\
\text { Variables }\end{array}$ & CPM & PBC & EEF & PF \\
\hline PEU & $\begin{array}{l}0.229 \\
(2.388)^{*}\end{array}$ & & & \\
\hline CPM & & $\begin{array}{l}0.631 \\
(8.367)^{* *}\end{array}$ & $\begin{array}{l}0.048 \\
(0.361)\end{array}$ & $\begin{array}{l}-0.053 \\
(0.534)\end{array}$ \\
\hline PBC & & & $\begin{array}{l}0.300 \\
(2.198)^{*}\end{array}$ & $\begin{array}{l}0.141 \\
(1.391)\end{array}$ \\
\hline EEF & & & & $\begin{array}{l}0.612 \\
(9.072)^{* *}\end{array}$ \\
\hline Adjusted $\boldsymbol{R}^{2}$ & 0.052 & 0.398 & 0.110 & 0.429 \\
\hline
\end{tabular}

PEU $=$ Perceived Environmental Uncertainty

$\mathrm{CPM}=$ Comprehensive Performance Measure

$\mathrm{PBC}=$ Performance Based Compensation

$\mathrm{EEF}=$ Employee Effort

$\mathrm{PF}=$ Organizational Performance

$* p<0.05$ (2-tailed)

$* * p<0.01$ (2-tailed)

Hypothesis 1 stipulated that perceived environmental uncertainty is positively associated with use of comprehensive performance measurement systems. Our results (reported in Table 4 and Figure 1) show that PEU is significantly and positively related to $\mathrm{CPM}(\beta=0.229, t=2.388, p<0.05$, two-tailed). Thus, $\mathrm{H} 1$ is supported.

Hypothesis 2 postulated that the use of comprehensive performance measures is positively associated with organizational performance. We do not find a significant bivariate correlation between CPM and PF $(0.181, p>0.05$, Table 3$)$, nor do we find a significant relationship once the direct effects of EEF and $\mathrm{PBC}$ on $\mathrm{PF}$ are controlled for ( $\beta=-0.053, t=0.534, p>0.05$, Table 4 and Figure 1$)$. Thus, $\mathrm{H} 2$ is not supported.

Hypothesis 3 predicted a positive relation between use of comprehensive performance measures and employee effort. The positive and significant bivariate correlation between $\mathrm{CPM}$ and $\operatorname{EEF}(0.237, p<0.05$, Table 3$)$ lends some initial support to this hypothesis. However, once the effect of PBC is included in our structural model, the path between CPM and EEF becomes insignificant $(\beta=0.048, t=0.361, p>0.05$, Table 4 and Figure 1). Thus, H3 also is not supported.

Hypothesis 4 stipulated that use of performance-based compensation increases with the use of comprehensive performance measures. This prediction is supported, as Table 4 and Figure 1 show that the 0.631 path coefficient between CPM and PBC in the structural model is statistically significant $(t=8.367, p<0.01$, two-tailed).

Hypothesis 5 stated that the use of performance-based compensation is positively associated with employee effort. Both the bivariate correlation between PBC and EEF $(0.330, p<0.01$, Table 3$)$ and path between $\mathrm{PBC}$ and EEF in the structural model after controlling for the effect of CPM on $\operatorname{EEF}(\beta=0.300, t=2.198, p<0.05$, two-tailed, Table 4 and Figure 1) are significant. These results provide support for H5. 
In addition, the results for $\mathrm{H} 3, \mathrm{H} 4$ and $\mathrm{H} 5$ together indicate that the relationship between CPM and EEF is fully mediated by PBC, according to the guidelines of Baron and Kenny (1986). This is because the direct effect between CPM and EEF (without taking PBC into account) starts off as significant (bivariate correlation of $0.237, p<0.05$, Table 3), but loses its statistical significance once PBC is added to the model $(\beta=0.048$, $t=0.361, p>0.05)$, while both the paths from CPM to PBC ( $\beta=0.631, t=8.367, p<0.01$, two-tailed) and PBC to EEF ( $\beta=0.300, t=2.198, p<0.05$, two-tailed) are significant. In other words, once the effect of the increased use of performance-based compensation is taken into account, the increased use of comprehensive performance measures has no additional effect on employee effort.

Finally focusing on firm performance, hypothesis 6 stipulated that employee effort is positively associated with organizational performance. Our results show both a significant bivariate correlation between EEF and PF $(0.646, p<0.01$, Table 3$)$ as well as a significant path between EEF and PF once the direct effect of PBC on PF is included in the model $(\beta=0.612, t=9.072, p<0.01$, two-tailed, Table 4 and Figure 1$)$. We thus find support for H6.

In hypothesis 7 , we proposed that performance-based compensation is positively associated with organizational performance as well. While our results show a significant bivariate correlation between $\mathrm{PBC}$ and $\mathrm{PF}(0.310, p<0.01$, Table 3$)$, the path in the structural model once EEF is included is not significant $(\beta=0.141, t=1.391, p>0.05$, two-tailed, Table 4 and Figure 1). Thus H7 is not supported.

A further insight is available from taking the results for $\mathrm{H} 5, \mathrm{H} 6$ and $\mathrm{H} 7$ as a package, namely, that the relationship between PBC and PF is fully mediated by EEF. More specifically, the significant bivariate correlation between PBC and $\mathrm{PF}(0.310, p<0.01$, Table 3) becomes statistically insignificant in the structural model $(\beta=0.141, t=1.391$, $p>0.05)$ once $\mathrm{EEF}$ is included, while the paths from $\mathrm{PBC}$ to $\operatorname{EEF}(\beta=0.300, t=2.198$, $p<0.05)$ and from EEF to $\mathrm{PF}(\beta=0.612, t=9.072, p<0.01$, two-tailed $)$ are significant. Thus, the effect of $\mathrm{PBC}$ on organizational performance is totally explained by its effect on employee effort.

\section{Summary and Discussion}

Applying the partial least squares causal modeling technique to data from 84 Taiwanese firms in the telecommunications, electronics, and information technology sector, our results provide support to the following picture: firms respond to environmental uncertainty by increasing their use of comprehensive performance measurement systems. This increase, in turn, enables an increased use of performancebased compensation systems, and the latter motivates employees to increase their effort at work. Finally, the increased employee effort positively impacts organizational performance. Beyond the path to organizational performance from employee effort, neither comprehensive performance measurement nor performance-based compensation has additional impacts on organizational performance.

In their writing explicating and promoting use of the balanced scorecard, Kaplan and Norton (1996) have argued for the use of PBC based on the scorecard measures once the organization is used to its application (p. 283). While our study does not examine this 
linkage at the level of specific performance measures, we do show that firms increase their use of performance-based compensation under more comprehensive performance measurement systems. Combined with our finding that the effect of CPM on employee effort is fully mediated by the increased use of PBC that accompanies the increased use of CPM, this result strongly supports viewing the performance measurement and compensation systems as an integral whole. Moreover, the existence of multiple mediating effects - that of PBC on the relation between CPM and EEF, and that of EEF between $\mathrm{PBC}$ and $\mathrm{PF}$ - strongly endorses our use of a causal modeling technique that simultaneously considers all of the linkages among the variables, rather than examining relations in a piecemeal fashion.

Given the potential importance of the issues explored in this study, further research is needed to test its findings' robustness, refine its methodology, and increase its scope. Within the scope of the current study, there is room for obtaining responses from more managers per firm, increasing the number of firms in the sample, expanding the set of industries included, and sampling from other national settings beyond Taiwan. Another point worthy of note is that all of the data used in this study were obtained by means of a survey. It is well known that self-reported data are vulnerable to intentional and unintentional biases (e.g., social desirability, faulty and selective recall, see Podsakoff and Organ (1986). We have tried to reduce measurement error in the design and administration of the survey through the use of multiple respondents in each firm, consisting of a high-level manager and a human resource manager. We also have undertaken extensive assessment of the psychometric properties of each construct and provided evidence of each measure's reliability and validity. And by using PLS to analyze our structural model, we have attempted to reduce measurement error as PLS simultaneously assesses the measurement model along with the structural model. While these measures increase confidence in the findings, there remains room for further refinements, including obtaining data from other sources, such as firms' internal documents. An added impetus for method triangulation is that, as compared to other approaches (e.g., cases studies, experiments and archival analysis), survey data have limited ability to illuminate the nature of processes, causal relationships, and issues of "how" and "why", see Birnberg et al. (1990).

As for extending the scope of analysis, it is useful to recognize that many variables are multi- rather than uni-dimensional. For example, we had only measured the comprehensiveness of performance measurement and performance-based compensation at a generic level. There is room for expanding the details sought, perhaps to the level of the specific performance measures used, e.g., Van der Stede et al. (2006). Doing so will permit a more precise matching between performance measurement and compensation (e.g., the relative weights placed on financial and non-financial performance measures), thus a more powerful test of performance effects. Beyond dis-aggregation, there is room for broadening the set of variables in the analysis. For example, future research could examine how individuals' risk preferences may affect their response to different forms and mixes of performance measurement and compensation. Furthermore, it is well known that performance measurement is only one aspect of companies' internal management systems. Other important aspects include the degrees of centralization/ decentralization, human resource management practices, organizational culture, and the 
behavior of people in superior positions, e.g., Bae and Lawler (2000), Daft (2001), Jung et al. (2003). It is important to explore how these other components of management systems and processes work together with performance measurement and compensation to affect organizational success.

\section{References}

Abernethy, M.A., and A.M. Lillis, 1995, "The Impact of Manufacturing Flexibility on Management Control System Design", Accounting Organizations and Society 20(4), 241-258.

Bae, J., and J. Lawler, 2000, “Organizational and HRM Strategies in Korea: Impact on Firm Performance in an Emerging Economy", Academy of Management Journal 43(3), 502-517.

Baiman. S., 1990, "Agency Research in Managerial Accounting: A Second Look", Accounting, Organizations and Society 15(4), 341-371.

Baiman, S., and M. V. Rajan, 1995, "The Informational Advantage of Discretionary Bonus Schemes, The Accounting Review 70(4), 557-579.

Baker, G., R. Gibbons, and K. J. Murphy, 1994, "Subjective Performance Measures in Optimal Incentive Contracts", Quarterly Journal of Economics 109(4), 1125-1156.

Balkin, D.B., G. D. Markman, and L. R. Gomez-Mejia, 2000, "Is CEO Pay in High-Technology Firms Related to Innovation?", Academy of Management Journal 43(6), 1118-1129.

Banker, R.D., G. Potter, and D. Srinivasan, 2000, “An Empirical Investigation of an Incentive Plan that Includes Nonfinancial Performance Measures", The Accounting Review 75(1), 65-92.

Barclay, D.W., C. Higgins, and R. Thompson, 1995, “The Partial Least Squares (PLS) Approach to Causal Modeling: Personal Computer Adaptation and Use as an Illustration", Technology Studies 2(2), 285-309.

Baron, R.M., and D. A. Kenny, 1986, "The Moderator-mediator Variable Distinction in Social Psychological Research: Conceptual, Strategic, and Statistical Considerations", Journal of Personality and Social Psychology 51(6), 1173-1182.

Bonner, S. E., Hastie, R., Sprinkle, G. B., and S.M. Young, 2000, "A Review of the Effects of Financial Incentives on Performance in Laboratory Tasks: Implications for Management Accounting”, Journal of Management Accounting Research 12, 19-64.

Bonner, S.E., and G.B. Sprinkle, 2002, "The Effects of Monetary Incentives on Effort and Task Performance: Theories, Evidence, and a Framework for Research", Accounting, Organizations and Society 27(4/5), 303-345.

Birnberg, J., M. Shields, and S. M. Young, 1990, The Case for Multiple Methods in Empirical Management Accounting Research (With an Illustration from Budget Setting), Journal of Management Accounting Research 2, 33-66.

Brislin, R. W., 1986, The Wording and Translation of Research Instruments, in: W. J. Lonner and J. W. Berry, eds., Field Methods in Cross-cultural Research (Sage: Newbury Park, CA), 1337-1364.

Burns, T., and G. Stalker, 1961, The Management of Innovation (Travistock: London, UK). 
Carey, J.M., and A. Nahavandi, 1996, Using Impression Management to Establish Successful Service-level Agreements, in: J.W. Beard, ed., Impression Management and Information Technology (Quorum Books: Westport, CN), 51-64.

Chenhall, R.H., 2003, "Management Control Systems Design Within its Organizational Context: Findings from Contingency-based Research and Directions for the Future", Accounting, Organizations and Society 28(2/3), 127-168.

Chenhall, R.H., 2004, "The Role of Cognitive and Affective Conflict in Early Implementation of Activity-based Cost Management", Behavioral Research in Accounting 16, 19-44.

Chenhall, R. H., 2005, "Integrative Strategic Performance Measurement Systems, Strategic Alignment of Manufacturing, Learning and Strategic Outcomes: An Exploratory Study", Accounting, Organizations and Society 30(5), 395-422.

Chenhall, R. H., 2007, "Theorizing Contingencies in Management Control Systems Research", in: C. S. Chapman, A. G. Hopwood, and M. D. Shields, eds., Handbook of Management Accounting Research, Vol. 1 (Elsevier: Oxford, UK), 163-206.

Chenhall. R.H., and D. Morris, 1986, "The Impact of Structure, Environment, and Interdependence on the Perceived Usefulness of Management Accounting Systems", The Accounting Review 61(1), 16-35.

Chin, W.W., 1998a, "Issues and Opinions on Structural Equation Modeling”, MIS Quarterly 22(1), vii-xvi.

Chin, W.W., 1998b, The Partial Least Square Approach to Structural Equation Modeling. in: G.A. Marcoulides, ed., Modern Methods for Business Research, (Lawrence Erlbaum Associates: Mahwah, New Jersey).

Chin, W.W., and A. Gopal, 1995, "Adopting Intention in GSS: Relative Importance of Beliefs", Data Base 26(2/3), 42-63.

Chong, V.K., 1996, "Management Accounting Systems, Task Uncertainty and Management Performance: A Research Note", Accounting, Organizations and Society 21(5), 415-421.

Chong, V.K., and K.M. Chong, 1997, "Strategic Choices, Environmental Uncertainty and SBU Performance: A Note on the Intervening Role of Management Accounting Systems", Accounting and Business Research 27(4), 268-276.

Chow, C., M. Shields, and A. Wu, 1999, "The Importance of National Culture in the Design of Management Control for Multi-national Operations", Accounting, Organizations and Society 24(5/6), 441-461.

Daft, R.L., 2001, Organization Theory and Design, (South-Western College Publishing: Cincinnati, $\mathrm{OH}$ ).

Datar, S., S. Kulp, and R. Lambert, 2001, "Balancing Performance Measures”, Journal of Accounting Research 39(1), 75-92.

Dempster, A.P., N. M. Laird, and D.B. Rubin, 1977, "Maximum Likelihood for Incomplete Data via the EM Algorithm", Journal of the Royal Statistical Society, Series B, 39(1), 1-38.

Dill, W., 1958, "Environment as an Influence on Managerial Autonomy", Administrative Science Quarterly 2(4), 409-444.

Eccles, R.G., 1991, “The Performance Measurement Manifesto”, Harvard Business Review 69 (January-February), 131-137. 
Epstein, M., and J. Manzoni, 1998, "Implementing Corporate Strategy: From Tableaux de Bord to Balanced Scorecards", European Management Journal 16(2), 190-203.

Feltham, G. A., and J. Xie, 1994, "Performance Measure Congruity and Diversity in Multi-Task Principal-Agent Relations", The Accounting Review 69(3), 429-453.

Fisher, J., 1992, "Use of Nonfinancial Performance Measures", Journal of Cost Management 6(1), 31-38.

Fornell, C., and D. Larcker, 1981, "Evaluating Structural Equation Models with Unobservable Variables and Measurement Error", Journal of Marketing Research 18(1), 39-50.

Galbraith, J., 1973, Designing Complex Organizations, (Addison Wesley Publishing: Reading, MA).

Gerdin, J., and J. Greve, 2004, "Forms of Contingency Fit in Management Accounting Research -- A Critical Review", Accounting, Organizations and Society 29(3/4), 303-326.

Gordon, L.A., and V.K. Narayanan, 1984, "Management Accounting Systems, Perceived Environmental Uncertainty and Organizational Structure: An Empirical Investigation", Accounting, Organizations and Society 9(1), 33-47.

Govindarajan, V., 1984, “Appropriateness of Accounting Data in Performance Evaluation: An Empirical Examination of Environmental Uncertainty as an Intervening Variables", Accounting, Organizations and Society 9(2), 125-135.

Gul, F.A., and Y.M. Chia, 1994, "The Effects of Management Accounting Systems, Perceived Environmental Uncertainty and Decentralization on Management Performance: A Test of Three Way Interaction", Accounting, Organizations and Society 19(4/5), 413-426.

Hall, M., 2007, “The Effect of Comprehensive Performance Measurement Systems on Role Clarity, Psychological Empowerment and Managerial Performance", Accounting, Organizations and Society (In Press).

Hair, J. F., R. E. Anderson, R. L. Tatham, and W.C. Black, 1998, Multivariate Data Analysis 5th Edition, (Prentice-Hall: Englewood Cliffs, NJ).

Hartmann, F.G.H. and F. Moers, 1999, “Testing Contingency Hypotheses in Budgetary Research: An Evaluation of the Use of Moderated Regression Analysis", Accounting, Organizations and Society 24 (4), 291-315.

Hayes, R. H., S. C. Wheelwright, and K. B. Clark, 1988, Dynamic Manufacturing, (Free Press: New York, NY).

Hemmer, T., 1996, "On the Design and Choice of "Modern" Management Accounting Measures", Journal of Management Accounting Research 8, 87-116.

Hirst, M., 1987, “The Effects of Setting Budget Goals and Task Uncertainty on Performance: A Theoretical Analysis", The Accounting Review 62(4), 774-784.

Hoffecker, J., and C. Goldberg, 1994, "Using the Balanced Scorecard to Develop Company-wide Performance Measures”, Journal of Cost Management 8(3), 5-17.

Holmstrom, B., 1979, "Moral Hazard and Observability", Bell Journal of Economics 10(1), 74-91.

Hopwood, A. G., 1974, Accounting and Human Behavior, (Haymarket Publishing: London, U.K). 
Hoque, Z., and W. James, 2000, "Linking Balanced Scorecard Measures to Size and Market Factors: Impact on Organizational Performance”, Journal of Management Accounting Research 12, 1-17.

Hulland, J., 1999, "Use of Partial Least Squares (PLS, in Strategic Management Research: A Review of Four Recent Studies”, Strategic Management Journal 20(2), 195-204.

Ittner, C.D., and D.F. Larcker, 1995, "Total Quality Management and the Choice of Information and Reward Systems", Journal of Accounting Research 33(1), 1-35.

Ittner, C. D., and D. F. Larcker, 1998, "Innovations in Performance Measurement: Trends and Research Implications", Journal of Management Accounting Research 10, 205-38.

Ittner, C., and D. Larcker, 2001, “Assessing Empirical Research in Managerial Accounting: A Value-based Management Perspective", Journal of Accounting and Economics (December), 349-410.

Ittner, C., D. Larcker, and M. Rajan, 1997, “The Choice of Performance Measures in Annual Bonus Contracts", The Accounting Review (April), 231-255.

Ittner, C., D. Larcker, and T. Randall, 2003, "Performance Implications of Strategic Performance Measurement in Financial Services Firms", Accounting, Organizations and Society 28(7/8), 715-741.

Jung, D., C. Chow, and A. Wu, 2003, “The Role of Transformational Leadership in Enhancing Organizational Innovation: Hypotheses and Some Preliminary Findings", The Leadership Quarterly 14, 525-54.

Kaplan, R. and D. Norton, 1992, "The Balanced Scorecard: Measures that Drive Performance", Harvard Business Review (January/February), 71-80.

Kaplan, R. and D. Norton, 1996, The Balanced Scorecard, (Harvard University Press: Boston MA).

Kaplan, R. and D. Norton, 2001, The Strategy Focused Organization: How Balanced Score Card Companies Thrive in the New Business Environment, (Harvard Business School Press: Boston. MA).

Khandwalla. P.N., 1972, "The Effect of Different Types of Competition on the Use of Management Controls", Journal of Accounting Research (Autumn), 275-285.

Khandwalla, P.N., 1977, The Design of Organizations, (Harcourt Brace Jovanovich: New York, NY).

Kren, L., and J.L. Kerr, 1993, "The Effect of Behaviour Monitoring and Uncertainty on the Use of Performance-contingent Compensation", Accounting and Business Research 23 (Spring), 159-168.

Lambert, R. A., 2001, "Contracting Theory and Accounting", Journal of Accounting and Economics 32 (1/3), 3-87.

Langfield-Smith, K., 2007, A Review of Quantitative Research in Management Control Systems and Strategy, in: C. S. Chapman, A. G. Hopwood, and M. D. Shields, eds., Handbook of Management Accounting Research, Vol. 1 (Elsevier: Oxford, UK), 753-784).

Lawler, E.E., 1973, Motivation in Work Organizations, (Jossey-Bass Publisher: San Francisco, CA).

Lawrence, P., and J. Lorsch, 1967, Organizations and Environment, (Irwin: Homewood. IL). 
Leifer, R., G.C. O’Connor, and M. Rice, 2001, “Implementing Radical Innovation in Mature Firms: The Role of Hubs", Academy of Management Executive 15(3), 102-113.

Little, R.J.A., and D.B. Rubin, 1987, Statistical Analysis with Missing Data, (John Wiley: New York, NY).

Luft, J. and M. D. Shields, 2003, "Mapping Management Accounting: Graphics and Guidelines for Theory-Consistent Empirical Research", Accounting, Organizations and Society 28 (2-3), 169-249.

Maisel, L.S., 1992, "Performance Measurement: The Balanced Scorecard Approach", Journal of Cost Management 6(2), 47-52.

Mia, L., and B. Clarke, 1999, "Market Competition, Management Accounting Systems and Business Unit Performance", Journal of Management Accounting Research 10(2), 137-158.

Neely, A., 1999, “The Performance Measurement Revolution: Why Now and What Next?", International Journal of Operations and Production Management 19(2), 205-228.

Nunnally, J.C., and I.H. Bernstein, 1994, Psychometric Theory 3rd Edition (McGrawHill: New York, NY).

Perrow, C., 1973, Organizational Analysis: A Sociological View, (Tavistock Publications: London UK).

Podsakoff, P.M., and D.W. Organ, 1986, "Self-reports in Organizational Research: Problems and Prospects", Journal of Management 12(4), 531-544.

Provost, L., and S. Leddick, 1993, "How to Take Multiple Measures to Get a Complete Picture of Organizational Performance", National Productivity Review (Autumn), 477-490.

Puranam, P., H. Singh, and M. Zollo, 2006, "Organizing for Innovation: Managing the Coordination-autonomy Dilemma in Technology Acquisitions", Academy of Management Journal 49(2), 263-280.

Robertson, S., 2005, An Examination of the Relationship between Performance Based Compensation Schemes and Performance Measurement Manipulation, (Unpublished PhD Thesis. The University of Melbourne).

Said, A. A., H. R. HassabElnaby, and B. Wier, 2003, “An Empirical Investigation of Performance Consequences of Nonfinancial Measures", Journal of Management Accounting Research 15, 193-223.

Sambamurthy, V., and W. Chin, 1994, "The Effects of Group Attitudes Toward Alternative GDSS Designs on the Decision-making Performance of Computersupported Groups", Decision Sciences 25(2), 215-241.

Schilling, M.A., and C. W. Hill, 1998, "Managing the New Product Development Process", Academy of Management Executive 12(3), 67-81.

Scott, T.W., and P. Tiessen, 1999, "Performance Measurement and Managerial Teams", Accounting, Organizations and Society 24(3), 263-286.

Shields, M.D., and S.M. Young, 1993, “Antecedents and Consequences of Participative Budgeting: Evidence on the Effects of Asymmetrical Information", Journal of Management Accounting Research (5), 265-280.

Snow, C., and L. Hrebiniak, 1980, "Strategy, Distinctive Competence, and Organizational Performance”, Administrative Science Quarterly 25, 317-366. 
Sosik, J.J., and A. C. Dworakivsky, 1998, "Self-concept Based Aspects of the Charismatic Leader: More than Meets the Eye", The Leadership Quarterly 9(4), 503-526.

Sprinkle, G. B., 2000, “The Effect of Incentive Contracts on Learning and Performance”, The Accounting Review 75(3), 299-326.

Stern, J.M., J. Shiely, and I. Ross, 2004, The EVA Challenge: Implementing Value-added Change in an Organization, (John Wiley and Sons Inc: New York, NY).

Tan, K-C., R.B. Handfield, and D.R. Krause, 1998, "Enhancing the Firm's Performance Through Quality and Supply Based Management: An Empirical Study”, International Journal of Production Research 36(10), 2813-2837.

Tan, K-C., V.R. Kannan, R. B. Handfield, and S. Ghosh, 1999, "Supply Chain Management: An Empirical Study of its Impact on Performance", International Journal of Operations and Production Management 19(10), 1034-1052.

Tymon Jr. W.G., D. E. Stout, and K.N. Shaw, 1998, "Critical Analysis and Recommendations Regarding the Role of Perceived Environmental Uncertainty in Behavioral Accounting Research", Behavioral Research in Accounting 10, 23-46.

Umanath, N.S., M. R. Ray, and T.L. Campbell, 1993, “The Impact of Perceived Environmental Uncertainty in Perceived Agent Effectiveness on the Composition of Compensation Contracts", Management Science 39(1), 32-45.

Van der Stede, W. A., C. W. Chow, and T. W. Lin, 2006, "Strategy, Choice of Performance Measures, and Performance", Behavioral Research in Accounting 18, 185-205.

Vroom, V.H., 1964, Work and Motivation, (Jossey-Bass: San Francisco, CA).

Wilcox, R., 1998, "How Many Discoveries have been Lost by Ignoring Modern Statistical Methods?”, American Psychologist 53(3), 300-314.

Wold, H., 1985, Systems Analysis by Partial Least Squares, in: P. Nijkamp, L. Leitner and N. Wrigley, eds., Measuring the Unmeasurable (Marinus Nijhoff: Dordecht: Bostong, MA), 221-252. 
